\title{
WestVirginiaUniversity
}

THE RESEARCH REPOSITORY @ WVU

Graduate Theses, Dissertations, and Problem Reports

2014

\section{Pausing of Children during Signaled and Unsignaled Transitions}

Apral P. Foreman

Follow this and additional works at: https://researchrepository.wvu.edu/etd

\section{Recommended Citation}

Foreman, Apral P., "Pausing of Children during Signaled and Unsignaled Transitions" (2014). Graduate Theses, Dissertations, and Problem Reports. 5611.

https://researchrepository.wvu.edu/etd/5611

This Thesis is protected by copyright and/or related rights. It has been brought to you by the The Research Repository @ WVU with permission from the rights-holder(s). You are free to use this Thesis in any way that is permitted by the copyright and related rights legislation that applies to your use. For other uses you must obtain permission from the rights-holder(s) directly, unless additional rights are indicated by a Creative Commons license in the record and/ or on the work itself. This Thesis has been accepted for inclusion in WVU Graduate Theses, Dissertations, and Problem Reports collection by an authorized administrator of The Research Repository @ WVU. For more information, please contact researchrepository@mail.wvu.edu. 
Pausing of Children during Signaled and Unsignaled Transitions

Apral P. Foreman
Thesis submitted
to the Eberly College of Arts and Sciences
at West Virginia University
in partial fulfillment of the requirements for the degree of
Master of Science in
Behavior Analysis

Claire St. Peter, Ph.D., Chair

Michael Perone, Ph.D.

Barry Edelstein, Ph.D.

Department of Psychology

Morgantown, West Virginia

2014

Keywords: Pausing; Transitions; Children; Problem Behavior Copyright 2014 Apral P. Foreman 


\section{ABSTRACT \\ Pausing of Children during Signaled and Unsignaled Transitions}

\section{Apral P. Foreman}

We evaluated effects of signaled and unsignaled transitions between reinforcement schedules on pausing and run rates of academic responding and rate and duration of problem behavior for four children who engaged in chronic and severe problem behavior. Children completed an academic task on a computer program to earn access to brief video clips. Lean (more responses and short videos) and rich (few responses and long videos) reinforcement schedules were alternated within each session, creating four transition types: lean-to-lean, lean-to-rich, rich-to-rich, and rich-tolean. Pausing was measured as the latency to initiate the first response of a reinforcement schedule. Run rates were calculated as responses per minute (minus pause durations). The rate and percentage of transitions with problem behavior during each transition type were also calculated. The results of all measures were idiosyncratic across participants. Potential explanations for the idiosyncratic results are discussed. 
PAUSING DURING TRANSITIONS

\section{Table of Contents}

Pausing of Children during Signaled and Unsignaled Transitions ................................................ 1

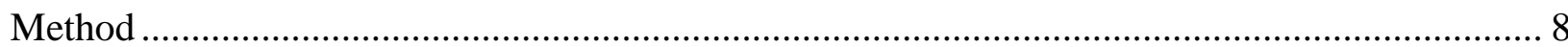

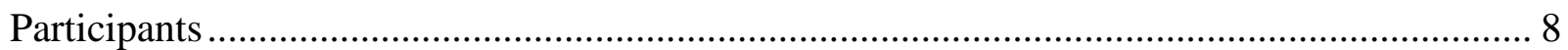

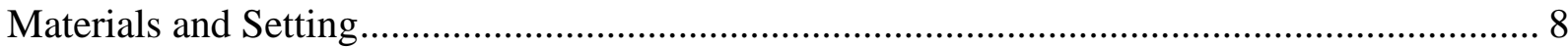

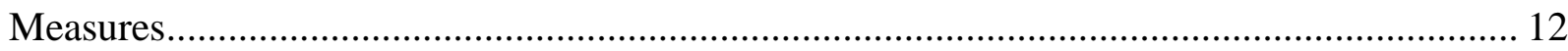

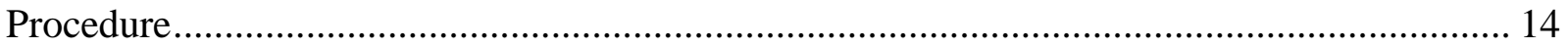

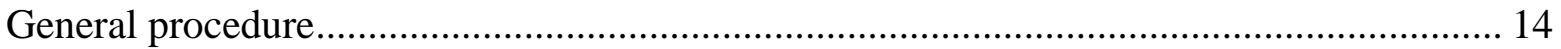

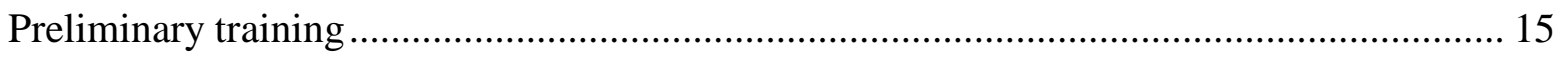

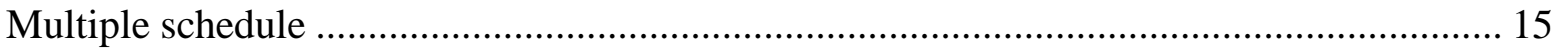

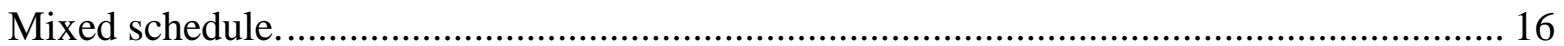

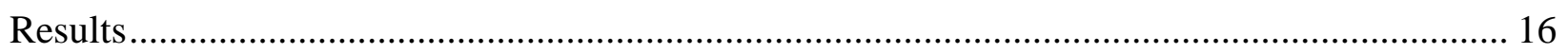

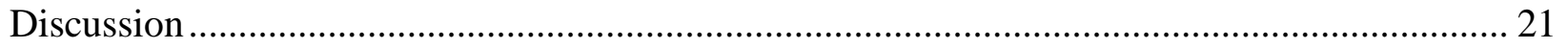

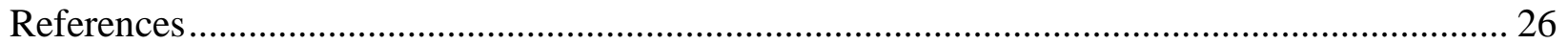

Tables and Figures ............................................................................................................. 30 
PAUSING DURING TRANSITIONS

Pausing of Children during Signaled and Unsignaled Transitions

Children experience transitions between activities daily. For some children, transitions evoke maladaptive behavior like noncompliance or aggression (Cale, Carr, Blakely-Smith, \& Owen-DeSchryver, 2009; Schreibman, Whalen, \& Stahmer, 2000). In addition, delayed academic, social skills, or vocational instruction may be correlated with difficult transitions. Those children who have difficulty completing transitions may have long-term skills deficits as a result of delayed instruction. Thus, understanding factors that contribute to successful transitions is important.

Transitions typically involve shifts between qualitatively or quantitatively different activities. For example, a common transition for children might involve changes in activities, such as coming in from recess and starting math. Dimensions of reinforcement associated with the past and upcoming activities may influence the probability that the transition will occur rapidly and in the absence of problem behavior. Transitioning to a highly reinforcing (preferred) activity may increase the likelihood of success, but transitioning away from that activity might be challenging (McCord, Thomson, \& Iwata, 2001; Waters, Lerman, and Hovanetz, 2009). Similarly, transitioning to a less-reinforcing (low-preferred) activity may be difficult, but transitioning away from that activity might be easier. For example, Waters et al. (2009) identified preferred and non-preferred activities for two boys diagnosed with autism. Then, the experimenters arranged transitions from no activity to a non-preferred activity and from a preferred activity to no activity. Challenging behavior in the form of aggression and disruption was evoked by transitioning to a non-preferred activity and by transitioning away from a preferred activity. 
PAUSING DURING TRANSITIONS

In laboratory studies, transitions can be arranged by having nonhuman animals respond during relative rich or lean reinforcement schedules. During a relatively rich reinforcement schedule, reinforcers are delivered frequently or for a low response requirement. During a relatively lean schedule, fewer reinforcers are delivered or the response requirement is higher. To the extent that these differences in schedules approximate the differences in qualitatively distinct transitions (like those between recess and math), laboratory studies may explain the circumstances under which transitions result in maladaptive behavior and the mechanisms responsible for that behavior.

Ratio-based reinforcement schedules are commonly used in the laboratory research on transitions. Ratio schedules require that the organism emit a certain number of responses to access a reinforcer. Typically, ratio schedules produce a "break-and-run” response pattern, in which organisms rapidly emit responses, earn a reinforcer, consume that reinforcer, and then pause before starting another rapid "run” of responses. Pausing during transitions between different ratio schedules is related to response requirement and reinforcer magnitude (e.g., Blakely \& Schlinger, 1988; Crossman, 1968, 1971; Felton \& Lyon, 1966; Harzem, Lowe, \& Davey, 1975; Harzem, Lowe, \& Priddle-Higson, 1978; Perone \& Courtney, 1992; Perone, Perone, \& Baron, 1987; Powell, 1968, 1969). The relation between response requirement and pausing is clear: As the response requirement increases, pause durations lengthen (Felton \& Lyon, 1966; Powell, 1968, 1969). However, the relation between reinforcer magnitude and pausing is not as clear. Some researchers have identified a positive relation, in which increases in reinforcer magnitude resulted in increases in pause durations (e.g., Lowe, Davey, \& Harzem, 1974; Priddle-Higson, Lowe, \& Harzem, 1976). Other researchers have identified an inverse 
PAUSING DURING TRANSITIONS

relation, in which increases in reinforcer magnitude resulted in decreases in pause durations (e.g., Blakely \& Schlinger, 1988; Powell, 1969).

These discrepant findings may be due to procedural variations across studies (Meunier \& Starratt, 1979; Perone \& Courtney, 1992; Schlinger, Derenne, \& Baron, 2008). One potentially important variable is the presence or absence of signals (e.g., colored lights) associated with changes between reinforcement schedules (Perone \& Courtney, 1992). When changes are unsignaled, pause duration increases following delivery of larger-magnitude reinforcers (e.g., Lowe et al., 1974; Priddle-Higson et al., 1976); the previously delivered reinforcer controls responding (Perone \& Courtney, 1992). Inhibitory aftereffects of reinforcer delivery may explain increased pausing following a large-magnitude reinforcer (Harzem et al., 1975; Harzem et al., 1978). When changes are signaled, pause duration decreases in the presence of the signal for the upcoming large-magnitude reinforcer (Blakely \& Schlinger, 1988; Powell, 1969); the upcoming reinforcer controls responding (Griffiths \& Thompson, 1973). Thus, signaled transitions result in short pauses when the upcoming ratio is associated with a large-magnitude reinforcer. Perone, et al. (1987) suggested that excitatory effects of the upcoming ratio may result in an inverse relation between pause duration and reinforcer magnitude. These excitatory effects produced by signals overshadow the inhibitory effects of the past reinforcer (Perone et al., 1987). Thus, when signals are present, the duration of the pause becomes a function of both the upcoming and past reinforcer magnitudes (Perone et al., 1987).

Perone and Courtney (1992) investigated the joint-control of past and upcoming reinforcer magnitude on pausing by manipulating whether stimuli signaling the upcoming reinforcer were present (multiple schedule) or absent (mixed schedule). Four White Carneau pigeons responded on alternating reinforcement schedules that produced short-duration (e.g., 2-s) 
PAUSING DURING TRANSITIONS

reinforcer access (labeled as “lean” schedules) or long-duration (e.g., 6-s) reinforcer access (labeled as “rich” schedules). The lean and rich schedules alternated semi-randomly, producing four transition types: lean-to-lean, lean-to-rich, rich-to-rich, and rich-to-lean. During mixedschedule phases, the key was lit the same color during both the lean and rich reinforcement schedules. Pausing was longer following rich components than lean components, and there was no effect of the upcoming reinforcer. During the multiple schedule, lean and rich reinforcement schedules were associated with distinct keylight colors. Pausing depended on both the past and the upcoming reinforcer durations. The longest pauses occurred when the past reinforcer duration was long (the "rich" condition) and the upcoming reinforcer duration was short (the “lean” condition). Perone and Courtney concluded that pausing is affected by both the past reinforcer duration and the upcoming reinforcer duration when reinforcement schedules are signaled.

Although pausing during transition has been examined primarily with non-humans, similar pausing may occur when children transition between activities. When it takes children a long time to transition to the next activity, academic instruction and reinforcers earned for working appropriately are delayed. In addition, challenging behavior during the transition may delay or eliminate the next activity. As a result, difficulty with transitioning between activities may result in academic, social, and vocational skills deficits. However, the degree to which pausing of humans is similar to that of non-human animals may depend on the type of reinforcer (e.g., points, coins, candy, etc.) and the type of response (e.g., telegraph key press, touch screen key press, etc.) being investigated (Schlinger et al., 2008).

Williams, Saunders, and Perone (2011) investigated how transitions between reinforcement schedules impacted the pause durations of seven intellectually disabled adults, 


\section{PAUSING DURING TRANSITIONS}

across three experiments. All experiments used a touchscreen computer and required the participants to respond by touching a square presented on the screen. Meeting the response requirement produced audible 2-s tones and yielded coins or points exchangeable for items. Lean reinforcement schedules involved large response requirements (e.g., 100 responses) to produce one tone and a small reinforcer (e.g., \$0.05). Rich reinforcement schedules involved relatively small response requirements (e.g., 10 responses) to produce three tones in a row and relatively larger reinforcers (e.g., \$0.25).

In Experiment 1, Williams et al. (2011) established extended pausing during rich-to-lean transitions. During preliminary training, participants were exposed to lean-to-lean, lean-to-rich, rich-to-rich, and rich-to-lean transitions in a semi-random alternating sequence. Touches to the square on the left were reinforced during the lean reinforcement schedule, and touches to the square on the right were reinforced during the rich reinforcement schedule. In addition to placing the square in different locations to facilitate discrimination between the reinforcement schedules, lean conditions were associated with one square color (e.g., a red square) and rich conditions were associated with a different square color (e.g., a yellow square). The response requirement, the reinforcer amount, or both were varied to establish longer pause durations during the rich-to-lean transitions. For all participants, longer pause durations occurred during the rich-to-lean transitions when there were large differences between the lean and rich schedules, when schedules were correlated with different colors (red or yellow), and when schedules required a different response (touching the square on the left or right).

In Experiment 2, Williams et al. (2011) used an A-B-A reversal design to investigate effects of schedule-correlated stimuli on pausing. The first phase (multiple schedule) used the same square colors and parameters established in Experiment 1. Completion of the response 
PAUSING DURING TRANSITIONS

requirement during rich reinforcement schedules produced one 2-s tone, a picture of a quarter, and a quarter was dispensed immediately from the coin dispenser. Completion of the response requirement during lean reinforcement schedules produced a different 2-s tone and the number " 1 ” on the screen; after the session, one penny was paid for each lean response requirement completed. During the mixed-schedule phase, reinforcement schedules were no longer correlated with different square colors. Instead, the background was blue across all sessions, and only one square (blue outlined in black) was presented on the screen. After meeting the response requirement, a novel 2-s tone sounded and the blue square was presented in the center of the screen.

Williams et al. (2011) replicated the results of Perone and Courtney (1992) with humans. Extended pausing was established during the rich-to-lean transitions by varying the disparity between the lean and rich reinforcement schedules (Experiment 1). In addition, extended pausing was established during rich-to-lean transitions under the multiple schedules but not under the mixed schedule (Experiment 2). These results provide supporting evidence for the joint-control of past and upcoming reinforcement conditions on human pausing during signaled transitions.

The results from highly controlled laboratory investigations of transitions between reinforcement schedules do not align with results from applied research on transitions in clinical contexts. Perone and Courtney (1992) and Williams et al. (2011) demonstrated that pausing (a maladaptive response) increased during signaled transitions from rich to lean reinforcement schedules, but not when the transitions were unsignaled. However, in applied research, signaling transitions is often suggested as a treatment component to increase successful transitions and reduce challenging behavior. In clinical studies, maladaptive behavior previously evoked by 
PAUSING DURING TRANSITIONS

transitions decreased when the transitions were signaled in advance (Flannery \& Horner, 1994;

Tustin, 1995). These signals may involve the use of activity schedules (Dettmer, Simpson, Myles, \& Ganz, 2000; Dooley, Wilczenski, \& Torem, 2001; Schmit, Alper, Raschke, \& Ryndak, 2000), auditory signals and verbal prompts (Ferguson, Ashbaugh, O’Reilly, \& McLaughlin, 2004; Sainato, Strain, Lefebvre, \& Rapp, 1987), and video-modeling (Cihak, Fahrenkrog, Ayre, \& Smith, 2010; Schreibman et al., 2000). Although the way in which signals were provided differ across studies, the effect of the signal was to reduce maladaptive behavior during the transition.

Procedural variations may account for the different outcomes across laboratory and clinical studies. In laboratory experiments, transitions typically involve changes in reinforcement rate or response requirement. Clinical studies typically evaluate transitions between qualitatively different activities. In laboratory research, signals (e.g., colored lights) are often scheduled to occur at the same time the transition occurs (e.g., Perone \& Courtney, 1992; Williams et al., 2011). Without these signals, it would be difficult for the organism to discriminate rapidly between reinforcement schedules. Because clinical research focuses on transitioning between activities, transition signals typically occur prior to the onset of the transition. Additionally, the shift between activities is typically discriminable even in the absence of advance signals. That is, transitioning from recess to math class involves a discriminable shift in environmental context, even without the addition of extra signals.

The current research attempted to begin bridging the gap between laboratory and clinical transition research. We attempted to replicate laboratory findings by using highly controlled shifts in reinforcement schedules, but conducting our study in a clinical (classroom) setting with highly verbal children who engage in chronic and severe problem behavior. We created 
PAUSING DURING TRANSITIONS

transitions between rich and lean reinforcement schedules and sometimes provided signals for those transitions. The signals we used were very similar to those used in laboratory research in that they occurred at the onset of the transition, not in advance. This preparation allowed us to include many of the features of laboratory studies (e.g., identical tasks across rich and lean schedules, quantitative differences in schedule, and signals at the time of transition onset). However, we also targeted the behavior of children who had a previous history of difficulty with naturally occurring transitions, in a typical classroom environment.

\section{Method}

\section{Participants}

Four children who engaged in chronic and severe problem behavior and had complex verbal repertoires participated in the experiment. Children attended an alternative education center that served students with emotional and behavioral disorders. Teachers reported that all children had difficulty with naturally occurring transitions throughout the school day. Parental consent and child assent were obtained prior to each child’s participation.

Harmony was a 9-year-old girl diagnosed with mild-moderate intellectual disability, Attention Deficit Hyperactivity Disorder (ADHD), Post Traumatic Stress Disorder (PTSD), and phonological disorder. Mitch was an 8-year-old boy diagnosed with ADHD and Oppositional Defiant Disorder (ODD). Miles was an 8-year-old boy diagnosed with Conduct Disorder - Not Otherwise Specified, Obsessive Compulsive Disorder (OCD), Attention Deficit Disorder (ADD), Asperger Syndrome, and ODD. Kyle was a 7-year-old boy diagnosed with ADHD.

\section{Materials and Setting}

Sessions took place in the children's classroom. Each child sat in a chair, at a desk or table, facing a $60.96 \mathrm{~cm}$ HP touch-screen computer monitor with headphones. Classroom staff 
PAUSING DURING TRANSITIONS

restricted access to all other items besides the computer and headphones. Some sessions were video recorded. For $71 \%$ of sessions, a researcher collected data on rates of problem behavior from live sessions or video records, using a computerized data-collection program that allowed time-stamped data records of response sequences.

A computer program presented all instructions, educational stimuli, and videos and collected data on several measures. The computer recorded a session event each time that the child initiated or completed a response, and whether the response was correct or incorrect. These data were used to evaluate the children's accuracy, latency to initiate a response, latency to complete a response, and reason for ending the session. Sessions were ended when the child completed 13 ratios, or after 30 min, whichever came first. Operational definitions for responses are shown in Table 1. The computer program added date and start time to the session log at the start of each session.

Students responded to a matching-to-sample task in which they matched pictures to printed words. The educational task was selected through an informal interview with the children's teachers about skills that would be appropriate for the student's age, developmental level, and current academic performance.

At the start of each session, the following text appeared on the computer screen: “Today we are going to match pictures to words. When each picture appears on the screen, touch the picture with your finger, pull your finger across the screen to the same colored box next to the word that matches the picture, and drop the picture into that box by lifting your finger. Sometimes you will get to take a break and watch a video for a little while. Let’s pick which video you want to watch during your breaks and begin working.” 
PAUSING DURING TRANSITIONS

The experimenter or teacher read the instructions aloud to the child before each session. The child touched the screen to select one of three available children's animated movies (i.e., Up, Madagascar, and Ratatouille), which were approved by the child's parent before the start of the experiment.

The first reinforcement schedule began immediately after the child selected a video. The program presented a series of trials, each consisting of a picture and three printed words. Figure 1 shows a screenshot of the computer program at the onset of a trial. The participant's initials were displayed in the upper left of the screen so that the teachers could ensure that the participant and data parameters matched. During each trial, a $4.45 \mathrm{~cm}$ by $5.72 \mathrm{~cm}$ picture was presented on the left of the screen. An array of three printed words appeared in a vertical array on the right of the screen. The words were each $30.48 \mathrm{~cm}$ from the picture. One of the three words matched the picture. For example, if the picture of a glass appeared as the sample stimulus, on the right of the screen, the words "glows," “gears,” and “glass” appeared.

The incorrect words originally selected all began with the same letter as the correct word. Accuracy was 73\% across the first 23 sessions for Mitch and below 40\% for Harmony (across first 23 sessions), Miles (across first 23 sessions), and Kyle (across first 18 sessions). The participants' teachers suggested changing the incorrect words to begin with a different letter than the correct comparison stimulus. For example, instead of the words "glows," "gears," and "glass” appearing on the right of the screen, “sciences," "kale,” and "glass” appeared. Changing the incorrect words resulted in improved accuracy for 3 of the 4 children. All data presented for Harmony, Mitch, Miles (except for the first phase), and Kyle are from sessions conducted after this change, and are discussed in more detail in the Results section. 


\section{PAUSING DURING TRANSITIONS}

The background was red, green, or grey, depending on the phase and reinforcement schedule in effect (discussed in more detail in the Procedure section). When the background was red or green, the picture also had a matching red or green border. Juxtaposed to the left of each word were two $5.40 \mathrm{~cm}$ by $6.67 \mathrm{~cm}$ response boxes, one red and one green (see Figure 1). Because the green response boxes were to the right of the red response boxes, the picture shifted to the right when the background color was green relative to when the screen was red. This ensured that the picture was always the same distance $(30.48 \mathrm{~cm})$ away from the appropriate colored box, regardless of the reinforcement schedule in effect.

The computer program randomly selected the picture for each trial without replacement from a bank of 24 possible stimuli. There were four possible words for each picture: the correct word and three incorrect words. Two of the three incorrect words were randomly selected during each trial. To move to the next trial, the child was required to touch and drag the picture into the same-colored box next to the correct word. When schedules were signaled (the background was either red or green), a correct response was matching a picture of a glass with a red border to the red box next to the word "glass" (see Figure 1). When the background was grey, there was only one set of response box next to each word (see Figure 2).

Children needed to complete a pre-specified number of correct responses to earn access to a video clip from the selected movie. If the child responded incorrectly (by selecting the wrong answer, the wrong color, or both), the position of comparison stimuli rotated, and same sample stimulus was presented until the child responded correctly. A brief video clip played once the child correctly completed the required number of trials for that schedule requirement. The required number of correct responses and duration of the video clip varied based on the reinforcement schedule in effect (see Procedure section, below, for details). Once the video clip 
PAUSING DURING TRANSITIONS

ended, the next response requirement began. Each time a video clip was earned by completing the ratio requirement, the video resumed where the last video clip ended.

\section{Measures}

The independent variables were the schedule type (mixed or multiple), the fixed-ratio (FR) requirement, and the reinforcer duration. The primary dependent measures included pause durations and run rates for each transition type. Only the first pause after a reinforcer delivery was analyzed. Pausing was defined as the latency to touch a picture on the first trial after a reinforcer delivery.

The mean pause durations were calculated for the four schedule transition types (lean-tolean, lean-to-rich, rich-to-rich, and rich-to-lean) using the data from the last five sessions of each phase (last three sessions for Harmony in the first multiple schedule and the mixed schedule). Pauses were analyzed after the last three sessions for Harmony during the first multiple schedule and the mixed schedule because her pause durations were stable via visual inspection. The other participants required five sessions to be considered stable via visual inspection.

Run rates were measured as the number of total responses (correct and incorrect) emitted to complete one ratio requirement, divided by the total time to complete that ratio requirement (response time) minus the latency to initiate the first response. Run rates were averaged for each participant, for each of the four transition types. Averages were calculated across the last five sessions of each phase (last three sessions for Harmony in the first multiple schedule and the mixed schedule).

Secondary dependent measures were response accuracy and problem behavior emitted during sessions. Response accuracy was measured by calculating the percentage of responses that correctly matched the picture to the word for each session. Accuracy data were 
PAUSING DURING TRANSITIONS

automatically collected by the computer program. Rates and percentage of transitions with problem behavior per phase and per transition type were collected and analyzed using a computerized data collection program from a randomly selected sample of at least three sessions per phase. See Table 2 for categories and operational definitions of problem behavior. Language and disruption were scored as frequencies and analyzed as rates. Out of seat, out of area, vocals, talking out, and turning the computer screen off were scored as durations and analyzed as percentage of the transition. We calculated rates of language and disruption by summing the total instances of language and disruption that occurred during each of the four transition types and dividing by the total duration of that transition type. Percentage of problem behavior (e.g., out of seat, vocals, talking out, etc.) was calculated by dividing the duration of problem behavior that occurred during each transition type by the total duration of that transition type and multiplying by $100 \%$.

A trained, independent observer collected interobserver agreement (IOA) data on rates of problem behavior from video records. IOA data were collected on $33 \%$ of sessions for which the primary researcher collected problem behavior data. We randomly selected sessions for which IOA data were collected across all phases of the experiment for each participant.

The computer program, Instant Rely, calculated the IOA between data collected by the two different observers by dividing each of the observer's data into 10-s intervals. For each 10-s interval, the program first calculated IOA for each key scored by at least one observer by dividing the larger count by the smaller count and converting to a percentage. For example, if Observer 1 scored disruption once and Observer 2 scored disruption twice during the first interval, the IOA for that interval would be (1/2)*100\%, yielding a score of 50\%. After calculating IOA between the two observers for each interval, the program averaged the scores 
PAUSING DURING TRANSITIONS

separately for each response to produce average IOA for each response, for that session. This process was completed for every target behavior. For Harmony, average IOA was 99.4\% (range 93.9-100.0\%). For Mitch, average IOA was 98.6\% (range 91.0-100.0\%). For Miles, average IOA was 99.4\% (range 95.2-100.0\%). For Kyle, average IOA was 95.6\% (range 72.2-100.0\%). See Table 3 for averages for each problem behavior for each participant.

\section{Procedure}

General procedure. Each transition type (lean-to-lean, lean-to-rich, rich-to-rich, and rich-to-lean) occurred at least three times during a session in a quasi-random order. The experimenter or teacher terminated the session if severe problem behavior occurred (e.g., forcefully banging on computer monitor, aggressive behavior, etc.) or if the child needed to use the restroom. If the session was terminated to allow the child to go to the restroom, a new session was started when the child returned to the classroom. Experimenters and teachers responded to severe behavior according to the child's established Behavior Support Plan or existing classroom procedures. Sessions in which the child did not complete all 13 transitions were labeled as incomplete sessions. We included data from incomplete sessions in the analysis only if the participant reached the 30-min time limit and had viewed at least six video clips. We did not include data from sessions terminated because of severe problem behavior or incomplete sessions during which the child viewed fewer than six video clips in the analysis. Experimental phases continued until successive pauses in each transition type showed no clear trend over the last five sessions of the phase (last three sessions for Harmony in the first multiple schedule and the mixed schedule). Sessions were conducted up to five days per week. The exact number of sessions per week depended on the child's availability. On average, two sessions were conducted per week for each child. Some sessions were recorded with a video camera. For 


\section{PAUSING DURING TRANSITIONS}

Harmony and Mitch, 89\% of sessions were recorded. For Miles 92\% of sessions were recorded, and for Kyle $100 \%$ of sessions were recorded.

Preliminary training. The background color during training was red or green and correlated with lean or rich reinforcement conditions, respectively. Pause durations during the four transition types were analyzed after every session. During rich schedules, two correct responses on the matching-to-sample task produced access to $30 \mathrm{~s}$ of the selected video clip (FR 2). The lean condition started as an FR 10, which produced access to a 15-s video clip.

If the initial parameters did not establish longer pausing during the rich-to-lean transitions than other transition types, the disparity between the rich and lean conditions was increased. The rich schedule remained an FR 2 with a 30-s reinforcer duration. The lean reinforcement schedule was made leaner by adding five responses to the response requirement and subtracting $5 \mathrm{~s}$ from the reinforcer duration. The reinforcer duration did not decrease below $5 \mathrm{~s}$, but the ratio requirement continued to be increased.

Multiple schedule. During multiple-schedule phases, the rich and lean reinforcement schedules were signaled at the start of the ratio by the background color of the computer screen. Because the procedures were similar to the preliminary training (with the exception that the schedule values remained fixed throughout the phase), the last five sessions of preliminary training were considered the first multiple-schedule phase if pauses were longest during rich-tolean transitions and not trending across successive responses. Because we erred in beginning the mixed schedule with Kyle, and did not identify this error until Kyle was no longer participating, we considered the last five sessions of preliminary training as the first multiple-schedule phase even though pausing was longest during the lean-to-lean transition and not the rich-to-lean transition type. 
PAUSING DURING TRANSITIONS

Mixed schedule. During the mixed schedule, the rich and lean schedules were no longer associated with distinct background colors on the computer screen. Instead, the screen remained grey throughout the session.

\section{Results}

After preliminary training, the lean schedule remained an FR10 with 15-s access to video for Miles and Kyle. For Miles, longer rich-to-lean pause durations were obtained with the initial parameters. For Kyle, the rich-to-lean transition periodically produced long pauses, but behavior was highly variable and mean pauses were longest in the lean-to-lean transition. Due to experimenter error, Kyle began the mixed schedule before longest pauses in the rich-to-lean transition were established or responding stabilized. For Harmony and Mitch, we increased the disparity until longer pausing occurred during the rich-to-lean transition across at least three sessions. This yielded terminal schedules of FR 25 with 5-s video access for Harmony, and FR 20 with 5-s video access for Mitch.

Data on the total number of sessions completed in each experimental phase, the number of sessions during which fewer than six video clips were viewed, the number of sessions that were aborted because of severe problem behavior or needing to use the restroom, and the average accuracy (shown as percentage correct) on the academic task are shown in Table 4. All data represent sessions conducted after the distractors were changed except for Mile’s first multipleschedule phase. The Total Sessions column depicts the total number of sessions conducted, including incomplete sessions. The Incomplete Sessions column shows the number of sessions in which the children completed fewer than six ratios within the 30-min time limit. These sessions were excluded from the data analysis. Across the experiment, the number of sessions in 
PAUSING DURING TRANSITIONS

which the children completed all 13 ratios increased. Thus, the number of sessions that were excluded from data analysis decreased. The Aborted Sessions column refers to sessions that had to be terminated by a teacher or experimenter due to severe problem behavior or to the child needing to use the restroom. The number of aborted and incomplete sessions also decreased across the phases of the experiment. The Average Accuracy column refers to the percentage of correct responses (i.e., correct match of the picture to the word). With the exception of Miles, all children were able to perform the picture-to-word matching with $90 \%$ or greater accuracy by the end of the mixed-schedule phase. Miles’ accuracy did not improve after the change in distractors. Harmony, Mitch, Miles, and Kyle accurately matched the color around the picture to the color of the response box for greater than 96\% of all responses (after distractor change); these data are not represented in Table 4.

Figures 3 and 4 shows mean pause durations and mean run rates (respectively) for the four transition types for each experimental phase. In both figures, the immediately preceding reinforcement schedule (lean or rich) is shown along the x-axis. The y-axis represents the mean pause duration in seconds for each transition type. Filled circles represent rich reinforcement conditions, and open circles represent lean reinforcement conditions. The error bars represent the standard deviations.

As shown in Figure 3, changes in mean pause durations across phases were not consistent. During the initial multiple schedule, mean pause durations for Harmony (upper graph), Mitch (upper-middle graph), and Miles (lower-middle graph) were slightly longer during the rich-to-lean transition type. Mean pause durations during the rich-to-lean transition for Miles were skewed due to one very long (180 s) pause during this transition type. For Kyle (bottom 
PAUSING DURING TRANSITIONS

graph), mean pause durations are longest during the lean-to-lean transition type, and there was a high degree of variability in pausing.

During the mixed schedule, there was no differentiation between mean pause durations for Harmony or Miles. For Mitch, mean pause durations became longer during the rich-to-lean transition type compared the other transition types, and to responding in the initial multiple schedule. However, this increase in mean pause duration seemed to be due to a small number of rich-to-lean transitions that evoked long pauses. For Kyle, mean pause durations remained variable and longest during the lean-to-lean transition type.

We were unable to recapture pause durations exhibited during the initial multiple schedule during the replication of that phase for Harmony, Mitch, or Miles. During the second multiple-schedule phase, Harmony paused for the longest mean duration during lean-to-lean transitions. Additionally, pausing became highly variable during this transition type. Harmony’s pausing continued to increase in the lean-to-lean transitions across the replication of the multiple-schedule phase. We attempted to conduct additional sessions to reduce the variability in her pausing in this transition type, but Harmony engaged in severe problem behavior during one session. The problem behavior was so severe that her crisis plan had to be implemented by the classroom teachers. After this session, teachers requested that we terminate Harmony’s participation to prevent future behavior problems within the classroom context. Pausing was largely undifferentiated for Mitch and Miles. For Kyle, mean pause durations remained longest during the lean-to-lean transition type.

Figure 4 shows mean run rates for each experimental phase. Overall, participants engaged in predictably lower run rates during lean schedules (shown in the open circles) relative to rich schedules (shown in the filled circles), regardless of the immediately preceding 
PAUSING DURING TRANSITIONS

reinforcement schedule. However, slightly higher run rates were obtained during rich-to-rich transitions than other transition types during 6 of the 8 multiple-schedule phases and 2 of the 4 mixed-schedule phases, across participants. During the initial multiple schedule, mean run rates for Harmony (upper graph) and Mitch (upper-middle graph) were slower when the upcoming reinforcer was lean than when the upcoming reinforcer was rich. For Miles (lower-middle graph) and Kyle (bottom graph), mean run rates were slower during the rich-to-lean transition than the other transition types, as predicted.

Results of the mixed-schedule phase are shown in the middle panel of Figure 4. For Harmony, Mitch, and Miles, mean run rates remained largely unchanged during the mixed schedule, despite the removal of the signals. Response variability increased somewhat for Mitch and Miles, although this increase did not appear to be associated with any particular transition type. For Kyle, mean run rates were not clearly differentiated across the four transition types. The replication of the multiple-schedule phase is shown in the third panel of Figure 4. During the replication of the multiple schedule, the overall pattern of mean run rates was consistent with the initial multiple-schedule phase for Mitch and Miles, although absolute rates varied slightly. For example, mean run rate decreased for Miles during rich-to-rich transitions. For Harmony mean run rate decreased during lean schedules and increased during the rich-torich transitions relative to the previous phases. For Kyle, the differentiation in mean run rates obtained during the first multiple-schedule phase was not replicated in the second exposure to multiple schedules. Kyle engaged in slightly faster run rates during the lean-to-rich transitions that the other transition types, and undifferentiated run rates during rich-to-lean and rich-to-rich transitions. 
PAUSING DURING TRANSITIONS

Figure 5 shows rates of inappropriate language and disruption for the four transition types by participant and phase, during the sessions that were randomly selected for analysis. Results were idiosyncratic across phases and participants. Data for Harmony are shown in the top graph. Harmony did not engage in inappropriate language or disruption during any of the sampled sessions (recall that Harmony’s participation was discontinued due to severe problem behavior during the final multiple-schedule phase, but this session was not one of the three randomly selected from this phase). Mitch (upper-middle graph) engaged in inappropriate language only during the rich-to-lean transitions in the initial multiple-schedule phase, but this result was not replicated in any other phase. Mitch engaged in language or disruption only during lean-to-lean transitions during the mixed schedule. Data for Miles are shown in the lower-middle graph. For Miles, language and disruption did not occur during the sampled sessions from the initial multiple-schedule phase. He engaged in more language and disruption during the rich-to-rich transitions in the mixed schedule, and exclusively during the lean-to-lean transitions of the second multiple-schedule phase. For Kyle (bottom graph), language and disruption occurred during the lean-to-lean transition type during the initial multiple-phase. During the mixed schedule no language or disruption occurred. During the final multiple-schedule phase, Kyle engaged in disruption during each transition type except for the rich-to-rich transition.

Figure 6 shows percentage of transition time with duration-based problem behavior (out of seat, out of area, vocals, talking out, and turning the computer screen off) for the four transition types, for each experimental phase. Similarly to the frequency measures, participants engaged in varying amounts of problem behavior across phases and transition types. For Harmony, duration-based problem behavior was not different across the four transition types during the mixed-schedule phase, and was more likely to occur during the rich-to-lean and lean- 
PAUSING DURING TRANSITIONS

to lean transitions than the other two transition types during second multiple-schedule phase.

During the first multiple schedule and the mixed schedule, Mitch also spent a greater proportion of rich-to-lean transitions engaging in problem behavior. However, Mitch engaged in the most problem behavior during the lean-to-lean transition in the replication of the multiple-schedule phase. Miles engaged in relatively little duration-based problem behavior during the sampled sessions. Results varied across phases for Kyle, who engaged in the most challenging behavior during the lean-to-lean, rich-to-rich, and rich-to-lean transitions across the three phases of the study.

\section{Discussion}

The purpose of the current research was to begin bridging the gap between laboratory and clinical transition research. To accomplish this, we attempted to establish pausing (extended latency to initiate first response), a measure typically used in laboratory research, with a clinical task and population. Specifically, we recruited children who engaged in chronic and severe problem behavior and asked them to complete an academic matching task. Second, we attempted to replicate procedures used in laboratory research by signaling transitions when the schedules changed instead of in advance of the transition, which is common in clinical research. Finally, we measured problem behavior occurring during a random sample of the signaled and unsignaled transitions. Both signaled and unsignaled transitions resulted in idiosyncratic and unsystematic pause durations, run rates, and problem behavior. The outcomes of this experiment did not align with those of Perone and Courtney (1992) or Williams et al. (2011). Several issues such as setting, noncompliance, reinforcement rate, task difficulty, and pause duration variability may have contributed to our results. 
PAUSING DURING TRANSITIONS

Unlike Perone and Courtney (1992) and Williams et al. (2011), the current experiment took place in an alternative education classroom. Other children, teachers, and staff were present during the sessions. It is possible that the variability in our results was due, at least in part, to uncontrolled sources of reinforcement available in the classroom context. We instructed the peers, teachers, and staff to minimize attention provided to the participants while the participants were working on the computer. However, we periodically observed individuals talking to the participants during sessions. Thus, unsystematic provision of attention may have resulted in a variable reinforcement schedule for behavior other than working on the computer (turning around, talking out, participating in ongoing classroom activities, etc.). Additionally, two of the four participants engaged in alternative activities (e.g., playing with string, chewing on the headphones) during at least one observed session. We attempted to restrict access to all other materials, but could not restrict materials like string on the participant's clothes, participants' hair, or materials necessary for the experimental session (i.e., the headphones). These items may have served as an uncontrolled alternative source of reinforcement.

These uncontrolled sources of alternative reinforcement may have caused intermittent long pauses in any of the transition types, resulting in excessive variability in responding and shifts in mean pause durations across phases. It is possible that analyzing our data using median pause durations instead of means would have yielded different results. However, emerging evidence suggests that extended pausing of humans during rich-to-lean transitions may occur because of a few very long pauses during this transition type (Williams et al., 2011). To be consistent with this evidence, we elected to use means. Future studies should compare our results to those obtained in a more controlled environment, such as an empty session room or laboratory, to isolate effects of differences in population, response topography, and setting. 
PAUSING DURING TRANSITIONS

Although participants were able to choose which video they would be working for prior to each session, we did not conduct a preference or reinforcer assessment to determine which videos to include in the array of choices. In addition, each time a video clip was earned by completing the ratio requirement, the video started where the last video clip ended. We programmed the computer this way to prevent satiation that may have occurred from watching the same clip repeatedly. However, the reinforcing value of any given clip may have varied depending on the scene in the video. For example, the reinforcing value of a character receiving bad news may be very different that the reinforcing value of a character receiving good news. It is also possible that there exists some minimum duration of access for video to function as a reinforcer- the relatively short durations that we used in the current study may have been insufficient. These factors may have influenced the participants’ willingness to work on the computer, both within and between sessions, rather than engage in other behaviors (e.g., talking out, playing with hair, etc.). Future research could use alternative reinforcers, such as edible items, or videos that could be entirely consumed in a brief period of time, such as commercials. Future studies should also include a reinforcer assessment to evaluate the reinforcing efficacy of the programmed consequences.

As further evidence that the videos may not have served as effective reinforcers, Miles and Kyle began to refuse to work on the computer after becoming familiar with the experimental arrangement. We hypothesized that the computer activity became aversive due to two potential factors. First, the task may have been more difficult than anticipated. Initially, the incorrect answers began and ended with the same letter as the correct stimulus. When this was the case, accuracy was at chance levels (approximately 33\% on average). Because the task was more difficult than expected, the participants were making several errors (range of 0-42 errors per 
PAUSING DURING TRANSITIONS

response requirement). To help overcome this issue, we made the incorrect answers more distinct from the correct answers, which increased accuracy for three of the participants. After the change, Harmony and Mitch seemed more willing to work on the computer, but Miles and Kyle still continued to intermittently refuse. Unfortunately, we did not anticipate this issue and therefore did not collect formal data on refusal. Future studies should probe performance on the task prior to the experiment to ensure the task is appropriate and collect data on events that happen during the transition to the computer session area to attempt to capture transition difficulties that may be evoked by the ongoing classroom activity.

The reinforcers provided as part of the ongoing classroom activity or the children's behavior intervention plans may have also influenced participants' willingness to work on the experimental task. The participants may have refused when the ongoing activity in the classroom was more reinforcing than the experimental contingencies. In other words, the start of an experimental session may have created a rich-to-lean transition between activities. Future research should continue to examine qualitative and quantitative differences between activities. It is possible that qualitative changes between activities result in more exacerbated disruptions in behavior than do the quantitative changes that we arranged in the current experiment.

It is also important to note that the sessions included in the analysis of problem behavior during the experiment were randomly selected for each phase. Although sessions included were selected at random, it is possible that one or more of those sessions were not representative of problem behavior overall. For example, for Harmony, one session that resulted in terminating the final multiple-schedule phase was not one of the randomly selected sessions included in the problem behavior analysis. However, randomly selecting sessions does help reduce the likelihood that sessions selected in any given phase were biased towards more or less problem 
PAUSING DURING TRANSITIONS

behavior. Future studies could collect data on problem behavior during every session to ensure those data were representative of performance throughout the experiment.

The purpose of this research study was to begin bridging the gap between laboratory and clinical transition research. Given the idiosyncratic results presented here, additional variables that may influence the effect of transitions on behavior may be important to transition research in clinical settings. In addition to manipulating reinforcement schedule parameters or changing between qualitatively different activities and using signals, identifying a potent reinforcer and controlling for alternative sources of reinforcement may be necessary to replicate pauses demonstrated by Perone and Courtney (1992) and Williams et al. (2011). Future researchers should take these additional variables into consideration as they continue to study transitions in clinical contexts. 
PAUSING DURING TRANSITIONS

\section{References}

Blakely, E., \& Schlinger, H. (1988). Determinants of pausing under variable-ratio schedules:

Reinforcer magnitude, ratio size, and schedule configuration. Journal of the Experimental Analysis of Behavior, 50(1), 65-73. doi:10.1901/jeab.1988.50-65

Cale, S. I., Carr, E. G., Blakeley-Smith, A., \& Owen-Deschryver, J. S. (2009). Context-based assessment and intervention for problem behavior in children with autism spectrum disorder. Behavior Modification, 33(6), 707-742. doi:10.1177/0145445509340775

Cihak, D., Fahrenkrog, C., Ayre, K. M., \& Smith, C. (2010). The use of video modeling via a video ipod and a system of least prompts to improve transitional behaviors for students with autism spectrum disorders in the general education classroom. Journal of Positive Behavior Interventions, 12(2), 103-115. doi:10.1177/1098300709332346

Crossman, E. K. (1968). Pause relationships in multiple and chained fixed-ratio schedules. Journal of the Experimental Analysis of Behavior, 11(2), 117-126. doi: 10.1901/jeab.1968.11-117

Crossman, E. K. (1971). The effects of fixed-ratio size in multiple and mixed fixed-ratio schedules. The Psychological Record, 21, 535-544.

Dettmer, S., Simpson, R. L., Myles, B. S., \& Ganz, J. B. (2000). The use of visual supports to facilitate transitions of students with autism. Focus on Autism and Other Developmental Disabilities, 15(3), 163-169. doi:10.1177/108835760001500307

Dooley, P., Wilczenski, F. L., \& Torem, C. (2001). Using an activity schedule to smooth school transitions. Journal of Positive Behavior Interventions, 3, 57-61. doi: $10.1177 / 109830070100300108$ 
PAUSING DURING TRANSITIONS

Felton, M., \& Lyon, D. (1966). The post-reinforcement pause. Journal of the Experimental Analysis of Behavior, 9(2), 131-134. doi:10.1901/jeab.1966.9-131

Ferguson, A., Ashbaugh, R., O’Reilly, S., \& McLaughlin, T. F. (2004). Using prompt training and reinforcement to reduce transition times in a transitional kindergarten program for students with severe behavior disorders. Child \& Family Behavior Therapy, 26, 17-24. doi:10.1300/J019v26n01_02

Flannery, K. B., \& Horner, R. H. (1994). The relationship between predictability and problem behavior for students with severe disabilities. Journal of Behavioral Education, 4(2), 157-176.

Griffiths, R., \& Thompson, T. (1973). The post-reinforcement pause: A misnomer. The Psychological Record, 23(2), 229-235.

Harzem, P., Lowe, C. F., \& Davey, G. C. L. (1975). After-effects of reinforcement magnitude: Dependence upon context. Quarterly Journal of Experimental Psychology, 27(4), 579584. doi:10.1080/14640747508400520

Harzem, P., Lowe, C. F., \& Priddle-Higson, P. J. (1978). Inhibiting function of reinforcement: Magnitude effects of on variable-interval schedules. Journal of the Experimental Analysis of Behavior, 30, 1-10. doi:10.1901/jeab.1978.30-1

Lowe, C. F., Davey, G. C. L., \& Harzem, P. (1974). Effects of reinforcement magnitude on interval and ratio schedules. Journal of the Experimental Analysis of Behavior, 22, 553560. doi:10.1901/jeab.1974.22-553

Meunier, G. F., \& Starratt, C. (1979). On the magnitude of reinforcement and fixed-ratio behavior. Bulletin of the Psychonomic Society, 13(6), 355-356. 
PAUSING DURING TRANSITIONS

McCord, B. E., Thomson, R. J., \& Iwata, B. A. (2001). Functional analysis and treatment of selfinjury associated with transitions. Journal of Applied Behavior Analysis, 34(2), 195-210. doi: 10.1901/jaba.2001.34-195

Perone, M., \& Courtney, K. (1992). Fixed-ratio pausing: Joint effects of past reinforcer magnitude and stimuli correlated with upcoming magnitude. Journal of the Experimental Analysis of Behavior, 57, 33-46. doi:10.1901/jeab.1992.57-33

Perone, M., Perone, C. L., \& Baron, A. (1987). Inhibition by reinforcement: Effects of reinforcer magnitude and timeout on fixed-ratio pausing. The Psychological Record, 37, 227-238.

Powell, R. W. (1968). The effect of small sequential changes in fixed-ratio size upon the postreinforcement pause. Journal of the Experimental Analysis of Behavior, 11(5), 589-593. doi:10.1901/jeab.1968.11-589

Powell, R. W. (1969). The effect of reinforcer magnitude upon responding on fixed-ratio schedules. Journal of the Experimental Analysis of Behavior, 12(4), 605-608. doi: 10.1901/jeab.1969.12-605

Priddle-Higson, P. J., Lowe, C. F., \& Harzem, P. (1976). Aftereffects of reinforcement on variable-ratio schedules. Journal of the Experimental Analysis of Behavior, 25(3), 347354. doi:10.1901/jeab.1976.25-347

Sainato, D. M., Strain, P. S., Lefebvre, D., \& Rapp, N. (1987). Facilitating transition times with handicapped preschool children: A comparison between peer-mediated and antecedent prompt procedures. Journal of Applied Behavior Analysis, 20, 285-291. doi: 10.1901/jaba.1987.20-285

Schlinger, H.D., Derenne, A., \& Baron, A. (2008). What 50 years of research tells us about pausing under ratio schedules of reinforcement. The Behavior Analyst, 31, 39-60. 
PAUSING DURING TRANSITIONS

Schmit, J., Alper, S., Raschke, D., \& Ryndak, D. (2000). Effects of using a photographic cueing package during routine school transitions with a child who has autism. Mental Retardation, 38(2), 131-137. doi:10.1352/00476765(2000)038<0131:EOUAPC>2.0.CO;2

Schreibman, L., Whalen, C., \& Stahmer, A. C. (2000). The use of video priming to reduce disruptive transition behavior in children with autism. Journal of Positive Behavior Interventions, 2, 3-11. doi:10.1177/109830070000200102

Tustin, R. D. (1995). The effects of advance notice of activity transitions on stereotypic behavior. Journal of Applied Behavior Analysis, 28, 91-92. doi:10.1901/jaba.1995.28-91

Waters, M. B., Lerman, D. C., \& Hovanetz, A. N. (2009). Separate and combined effects of visual schedules and extinction plus differential reinforcement on problem behavior occasioned by transitions. Journal of Applied Behavior Analysis, 42, 309-313. doi:

10.1901/jaba.2009.42-309

Williams, D. C., Saunders, K. J., \& Perone, M. (2011). Extended pausing by humans on multiple fixed-ratio schedules with varied reinforcer magnitude and response requirements. Journal of the Experimental Analysis of Behavior, 95(2), 203-220.

doi:10.1901/jeab.2011.95-203 
PAUSING DURING TRANSITIONS

Table 1

Operational Definitions of Responses

\begin{tabular}{ll}
\hline Aspect of Response & Operational Definition \\
\hline Latency to initiate a response & $\begin{array}{l}\text { Time, in milliseconds, it took child to initiate a } \\
\text { response by touching the picture. }\end{array}$ \\
Latency to complete a response & $\begin{array}{l}\text { Time, in millisceconds, it took child to drag } \\
\text { picture inside a response box after the first } \\
\text { touch to the picture. }\end{array}$ \\
Accurate response & $\begin{array}{l}\text { Matching the picture to the response box next } \\
\text { to the correct printed word. }\end{array}$ \\
Inaccurate response & $\begin{array}{l}\text { Matching the picture to the the response box } \\
\text { next to the incorrect printed word. }\end{array}$ \\
\hline
\end{tabular}


PAUSING DURING TRANSITIONS

Table 2

Operational definitions of each problem behavior included in the problem behavior data analysis

\begin{tabular}{|c|c|c|}
\hline Problem Behavior & Definition & Scoring Method \\
\hline Disruption & $\begin{array}{l}\text { Forceful contact with items or } \\
\text { forceful movement of items or } \\
\text { attempts (e.g., ripping materials, } \\
\text { banging/shaking computer } \\
\text { monitor) }\end{array}$ & Frequency \\
\hline Language & $\begin{array}{l}\text { Socially unacceptable words or } \\
\text { gestures (e.g., cursing, telling } \\
\text { someone to “shut up”) }\end{array}$ & Frequency \\
\hline Out Of Area & $\begin{array}{l}\text { Being more than } 2 \mathrm{ft} \text { away from } \\
\text { computer screen (immediate } \\
\text { onset, 2s offset) }\end{array}$ & Duration \\
\hline Out Of Seat & $\begin{array}{l}\text { Any time child's behind does not } \\
\text { have contact with the seat of the } \\
\text { chair ( } 2 \text { s onset/offset) }\end{array}$ & Duration \\
\hline Vocals & $\begin{array}{l}\text { Non-word sounds above } \\
\text { conversational volume with a 2s } \\
\text { onset/offset (e.g., crying barking) }\end{array}$ & Duration \\
\hline Talking Out & $\begin{array}{l}\text { Talking to a peer or adult in the } \\
\text { classroom (immediate } \\
\text { onset/offset) }\end{array}$ & Duration \\
\hline Turning Computer Off & $\begin{array}{l}\text { Pushing on/off button of the } \\
\text { computer monitor. (immediate } \\
\text { onset/offset of computer screen } \\
\text { going black) }\end{array}$ & Duration \\
\hline
\end{tabular}


PAUSING DURING TRANSITIONS

Table 3

Average percentage interobserver agreement scores (IOA) for each topography of problem behavior for each participant

\begin{tabular}{ccccccccc}
\hline & & & \multicolumn{3}{c}{ Out of } & Out of & \multicolumn{3}{c}{ Turning } \\
Participant & Disruption & Language & Area & Seat & Vocals & Out & $\begin{array}{c}\text { Computer } \\
\text { Off }\end{array}$ & $\begin{array}{c}\text { Overall } \\
\text { Average }\end{array}$ \\
\hline Harmony & 100.0 & 100.0 & 100.0 & 100.0 & 98.0 & 97.7 & 100.0 & 99.4 \\
Mitch & 99.8 & 99.8 & 99.8 & 94.6 & 98.9 & 97.6 & 100.0 & 98.6 \\
Miles & 99.7 & 100.0 & 100.0 & 99.4 & 98.1 & 99.0 & 99.7 & 99.4 \\
Kyle & 89.6 & 100.0 & 99.5 & 89.8 & 98.5 & 92.0 & 100.0 & 95.6 \\
\hline
\end{tabular}


PAUSING DURING TRANSITIONS

Table 4

Total number of sessions completed, number of sessions with fewer than six ratios completed, number of aborted sessions, and average response accuracy for each phase of the experiment.

\begin{tabular}{|c|c|c|c|c|}
\hline Participant & $\begin{array}{c}\text { Total } \\
\text { Sessions }\end{array}$ & $\begin{array}{c}\text { Incomplete } \\
\text { Sessions }(<6 \\
\text { Ratios) }\end{array}$ & $\begin{array}{l}\text { Aborted } \\
\text { Sessions }\end{array}$ & $\begin{array}{l}\text { Response } \\
\text { Accuracy }\end{array}$ \\
\hline \multicolumn{5}{|c|}{ Multiple Schedule (Phase 1) } \\
\hline Harmony & 18 & 1 & 1 & $72 \%$ \\
\hline Mitch & 10 & 0 & 1 & $95 \%$ \\
\hline Miles $^{\mathrm{a}}$ & 18 & 3 & 1 & $31 \%$ \\
\hline Kyle & 10 & 2 & 2 & $84 \%$ \\
\hline \multicolumn{5}{|c|}{ Mixed Schedule (Phase 2) } \\
\hline Harmony & 3 & 0 & 0 & $92 \%$ \\
\hline Mitch & 9 & 0 & 0 & $95 \%$ \\
\hline Miles & 36 & 0 & 1 & $34 \%$ \\
\hline Kyle & 17 & 1 & 1 & $93 \%$ \\
\hline \multicolumn{5}{|c|}{ Multiple Schedule (Phase 3) } \\
\hline Harmony & 5 & 0 & 0 & $92 \%$ \\
\hline Mitch & 5 & 0 & 0 & $96 \%$ \\
\hline Miles & 8 & 1 & 0 & $33 \%$ \\
\hline Kyle & 15 & 0 & 0 & $94 \%$ \\
\hline
\end{tabular}

${ }^{\mathrm{a}}$ Miles was in the mixed-schedule phase when the distractors were changed. For him, the entire multiple-schedule phase was completed with the old distractors. 


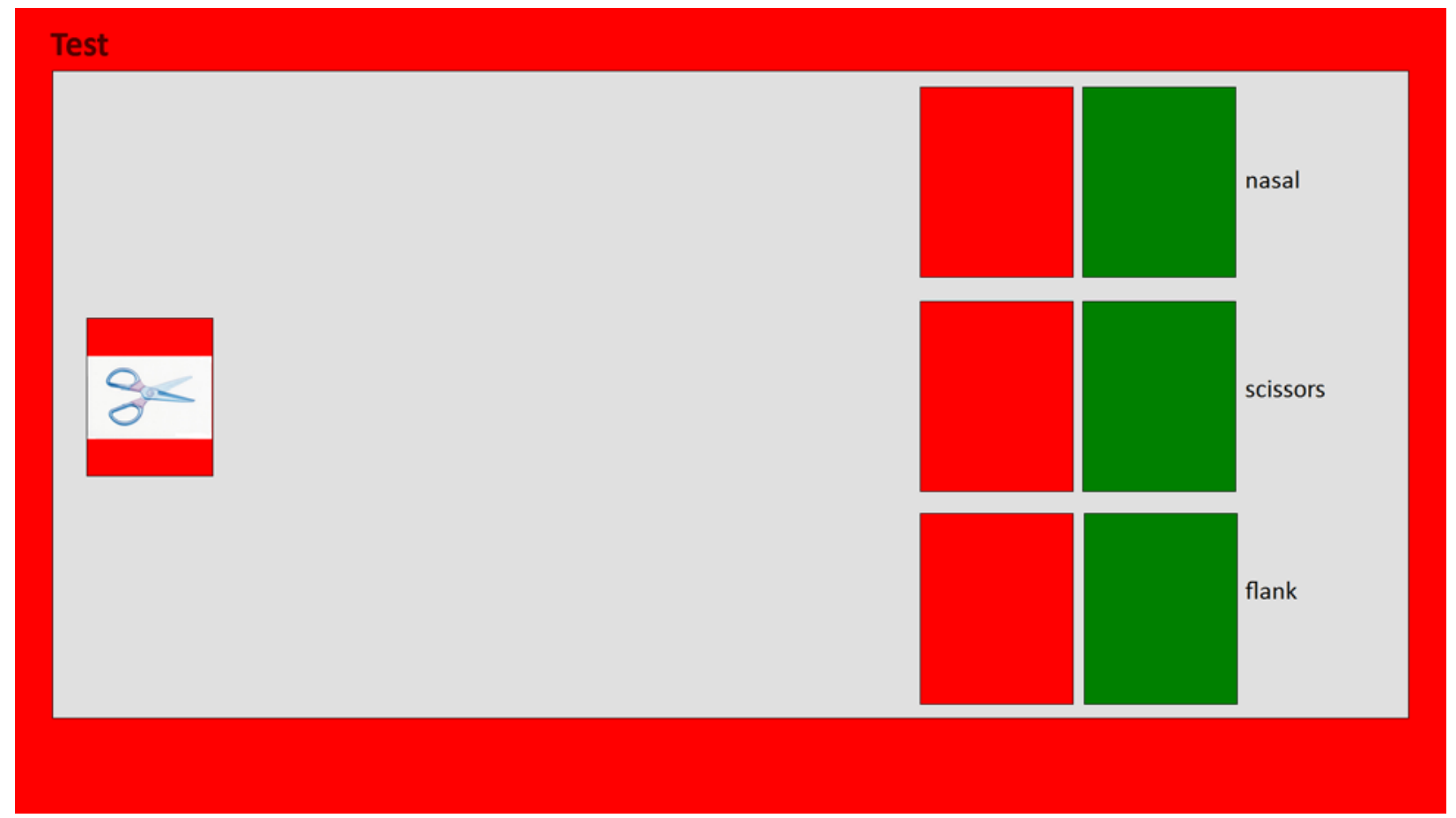

Figure 1. Screenshot of the computer program for the multiple schedule. On the left is the sample stimulus. On the right are the correct stimulus and distractor stimuli. In the background is the color associated with the reinforcement schedule in effect. 
PAUSING DURING TRANSITIONS

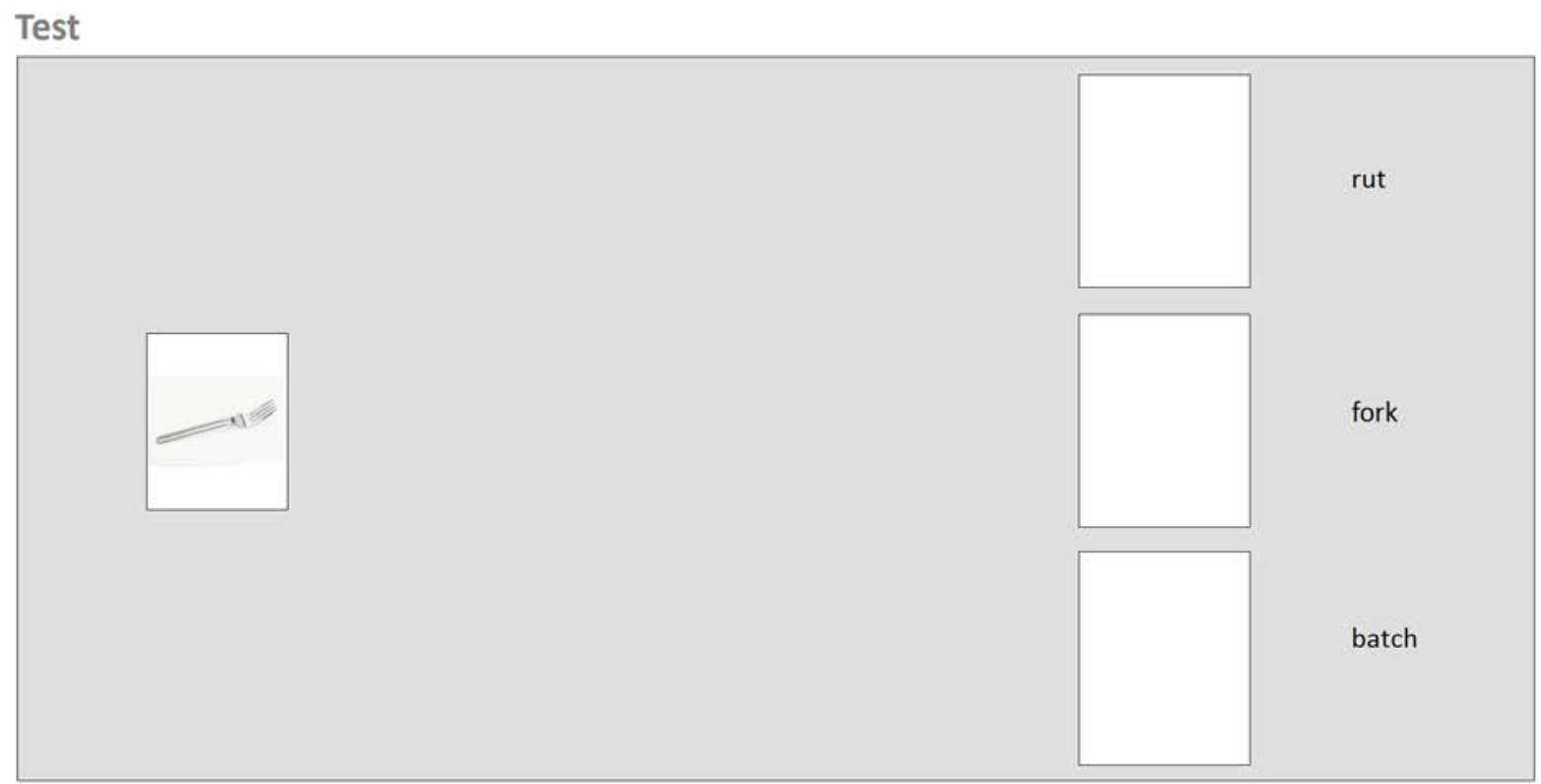

Figure 2. Screenshot of the computer program for the mixed schedule. On the left is the sample stimulus. On the right are the correct stimulus and distractor stimuli. The background is grey. 
PAUSING DURING TRANSITIONS
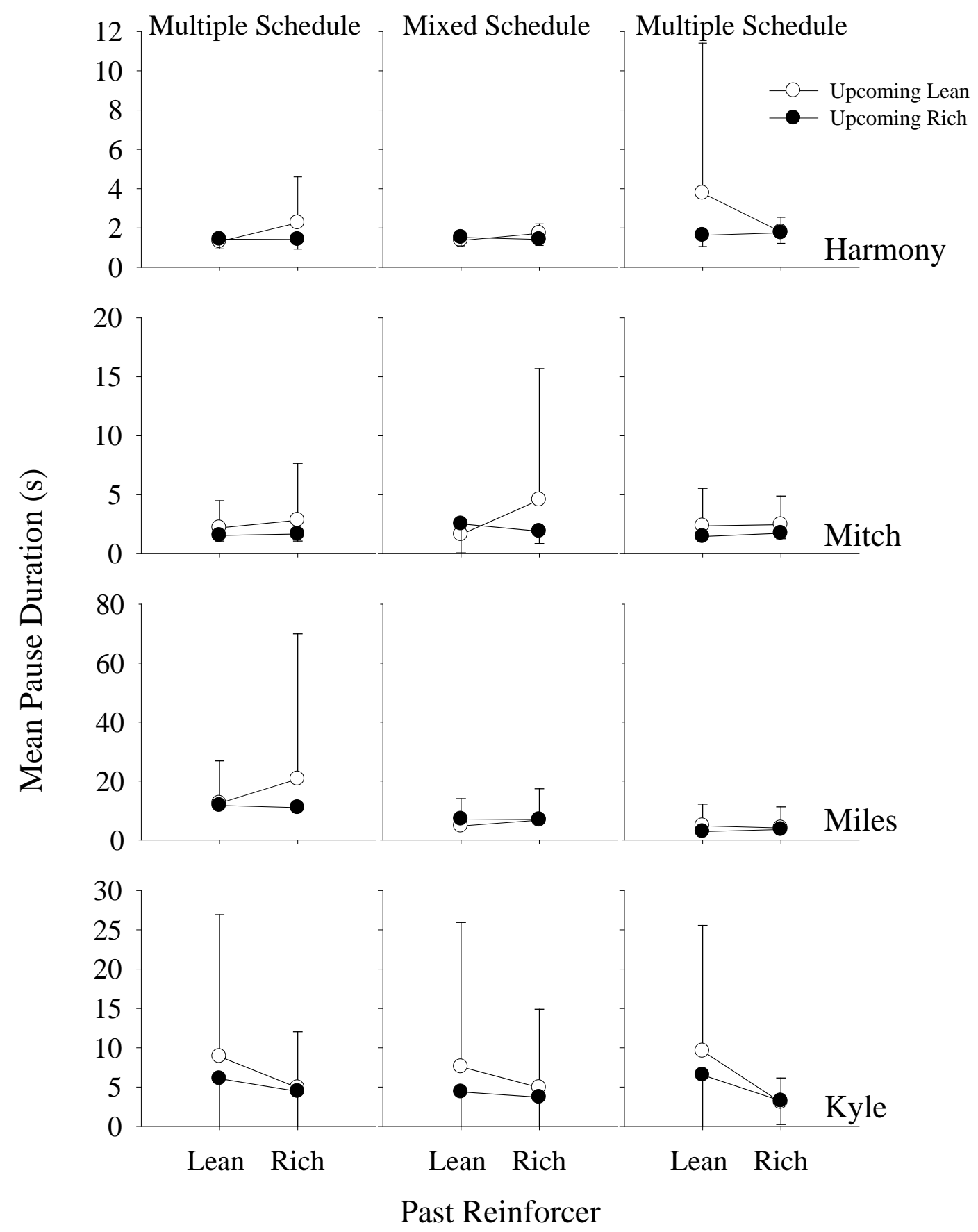

Figure 3. Mean pause durations and standard deviations in seconds for the four transition types, lean-to-lean, lean-to-rich, rich-to-rich, and rich-to-lean, for each experimental phase. The first and third panels show responding during multiple schedules. The second panel shows responding from a mixed schedule. Data are from the last five sessions of each phase for Mitch, Kyle, and Miles. Data are from the last three sessions of the first multiple and mixed schedules and the last five sessions of the second multiple for Harmony. 
PAUSING DURING TRANSITIONS
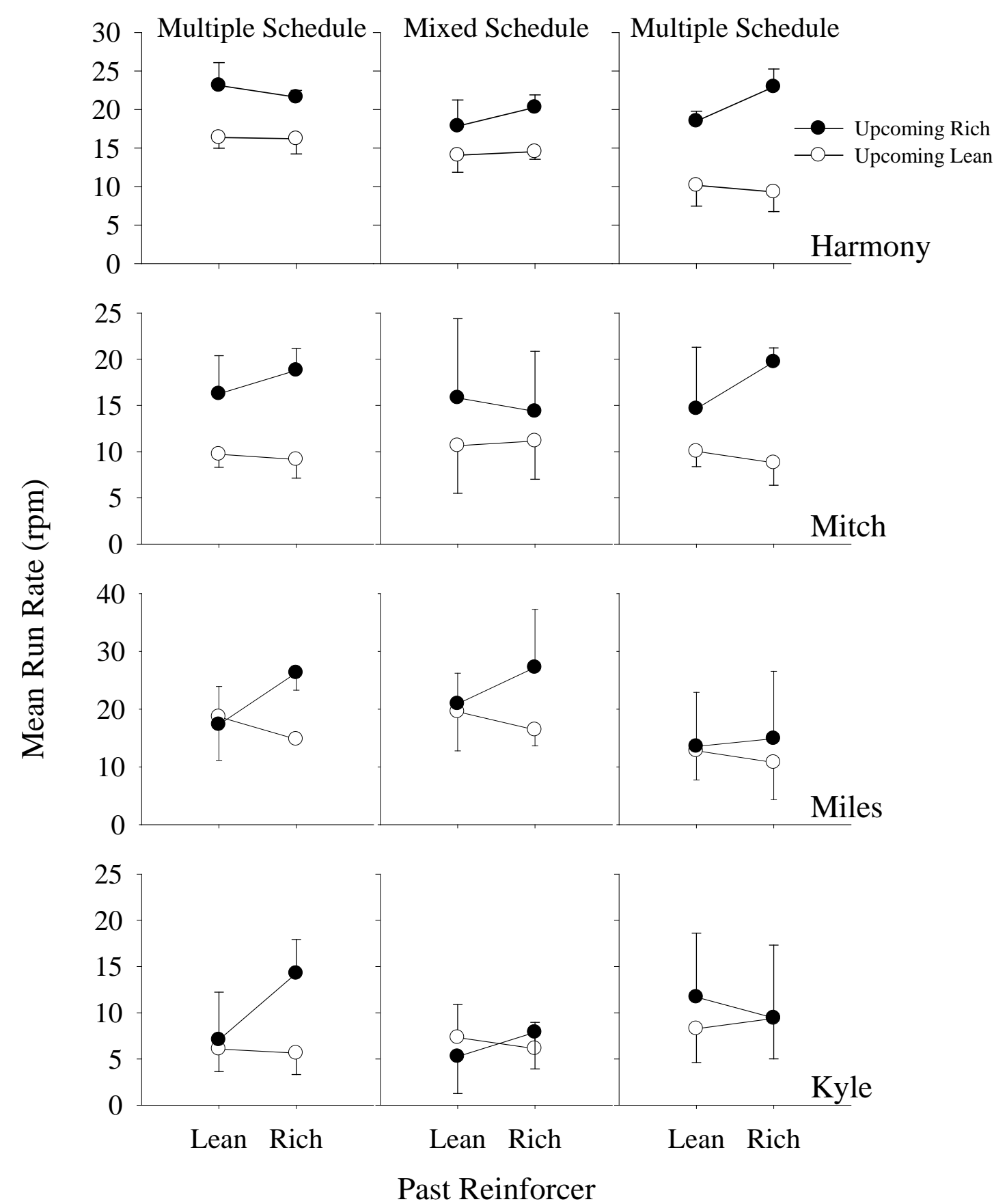

Figure 4. Mean run rates and standard deviations in responses per minute for the four transition types, lean-to-lean, lean-to-rich, rich-to-rich, and rich-to-lean, for each experimental phase. The first and third panels show responding during multiple schedules. The second panel shows responding from a mixed schedule. Data are from the last five sessions of each phase for Mitch, Kyle, and Miles. Data are from the last three sessions of the first multiple and mixed schedules and the last five sessions of the second multiple for Harmony. 
PAUSING DURING TRANSITIONS

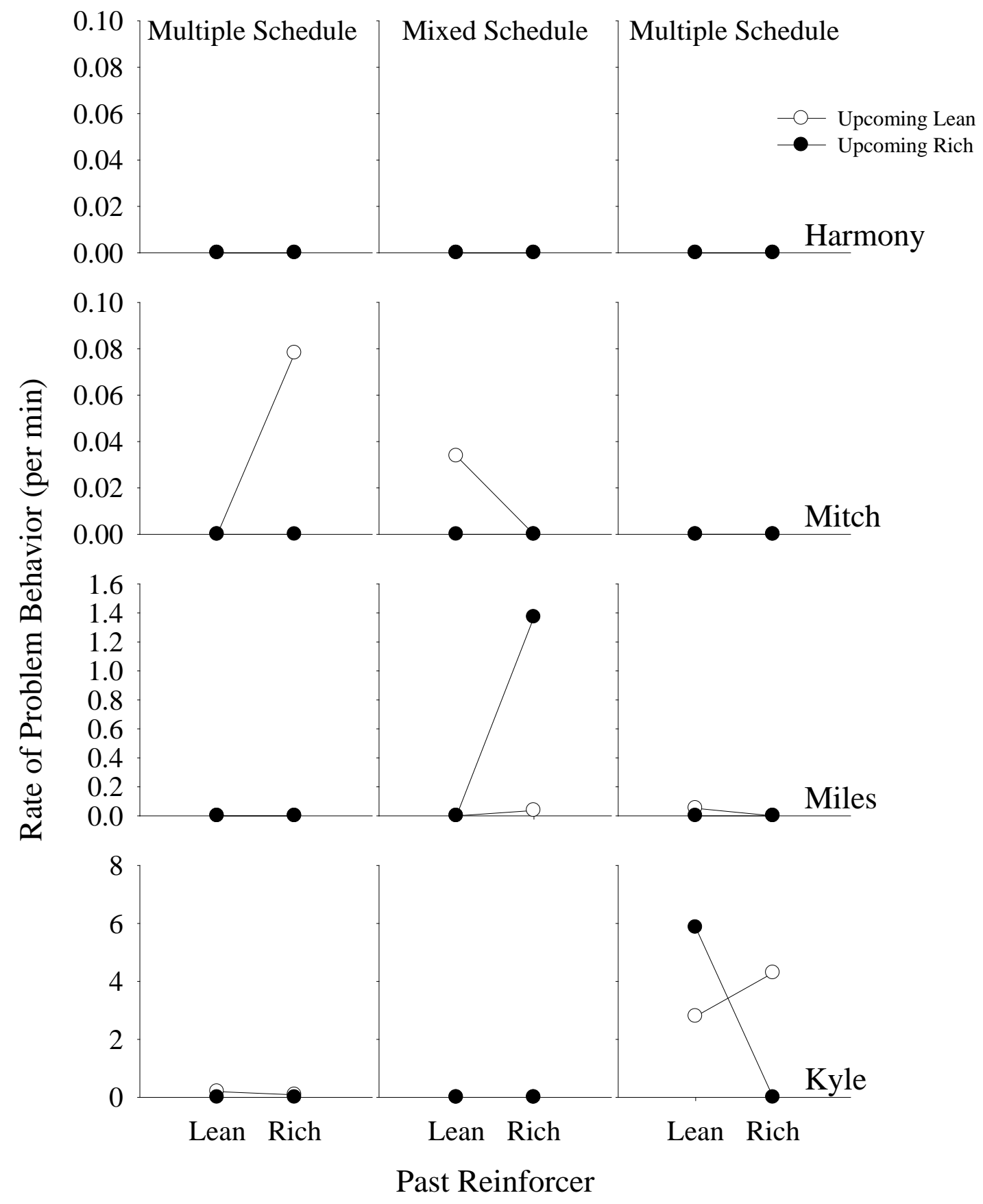

Figure 5. Rates of disruption and language for the four transition types, lean-to-lean, lean-to-rich, rich-to-rich, and rich-to-lean, for each experimental phase. The first and third panels show responding during multiple schedules. The second panel shows responding from a mixed schedule. Data are sampled from the last five sessions of each phase for Mitch, Kyle, and Miles. Data are sampled from the last three sessions of the first multiple and mixed schedules and the last five sessions of the second multiple for Harmony. 
PAUSING DURING TRANSITIONS
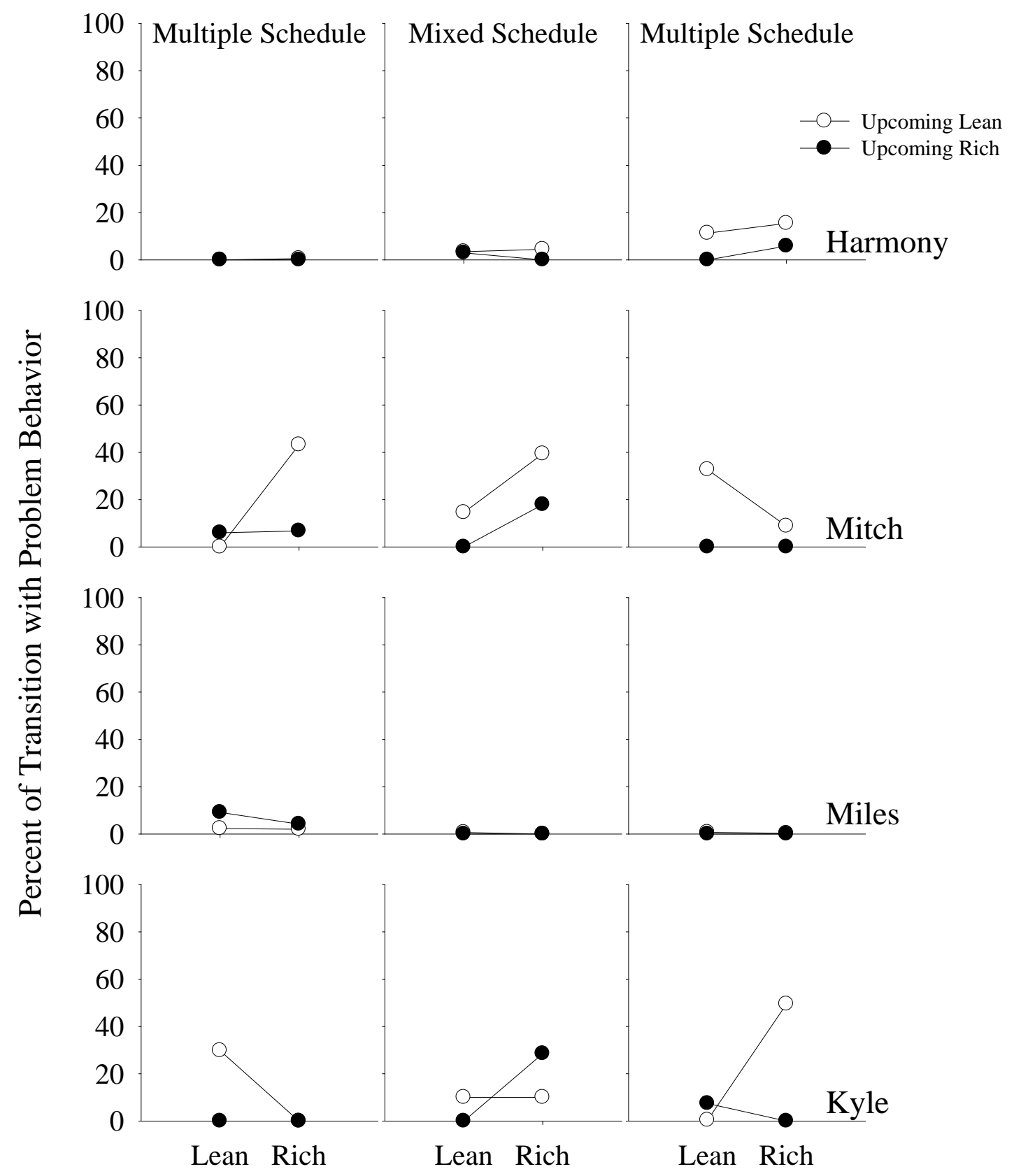

Past Reinforcer

Figure 6. Percent of transition with all other behaviors listed in Table 2 for the four transition types, lean-to-lean, lean-to-rich, rich-to-rich, and rich-to-lean, for each experimental phase. The first and third panels show responding during multiple schedules. The second panel shows responding from a mixed schedule. Data are sampled from the last five sessions of each phase for Mitch, Kyle, and Miles. Data are sampled from the last three sessions of the first multiple and mixed schedules and the last five sessions of the second multiple for Harmony. 